\title{
MUSTAFA KEMAL, AMASYA VE İKİ DİN ADAMI
}

\author{
Mevhibe SAVAS*
}

\section{AMASYA MÜFTÜSÜ HACI TEVFİK EFENDI}

19 Mayıs 1919 'da Samsun'a çıkan Mustafa Kemal Paşa; bölgedeki Pontus Rum çetelerinin tasallutundan İngiliz Entellicens Servisi'nin takibinden, General Milen'in baskısından, Rus heyetinin tekliflerinden kurtulup, uzun süreden beri tasarladıklarının temelini atacak bir yer bulabilmek için, Havzà'dan Amasya Müftüsü Hacı Tevfik Efendiye ${ }^{1}$ gönderdiği telgrafa umduğundan daha kısa bir zamanda gelen şu cevap ile aradığı yeri bulmuştu.

"- Amasya halk müdafa-i vatan, muhafaza-i din ve devlet yolunda mücahade edenleri bă̆rina basmakla müftehir olacaktır.

\section{Müftü Hacı Tevfik”2}

Paşa'nın Amasya'ya geleceği haberi alınınca karşılamak için müftü, vaiz, eşraf ve halk yollara dökülüir. Karşılayanlardan birinin hatıralarında;

“Paşa'yı Gezirlik Mevki'nde bekledik otomobille geldi. Önümüzde durdu. Hepimizi selamladı, ellerimizi sıktı"³ diye anlatırken Mustafa

* Cumhuriyet Üniv. Araştırma Görevlisi.

1. Hacı Hafız Tevfik Efendi; H.1282 (1868) senesinde Amasya'nın Fethiye Mahallesinde doğmuştur. Yumuk Osman zâde ailesindendir. Babası ilmiye sınıfından Amasya Müftü Müsevvidi Ahmet Şükrü Efendi'dir. Milli Mücadele esnasında Amasya'daki askerî birliğin başında bulunan Binbaşı Cemil Cahit Toydemir'in hatıralarında;

"O günlerde Müftü Hacı Hafız Tevfik Efendi kumandan, ben onun erkân-1 harbi idim. Ingiliz Entellicens Servisi'nin resmi kılıklı şeklî Binbaşısı Noil'in raporunda "Tahkik komisyonlarımızın beldelerine girmesini istemeyen ve icap ederse halkın silahlandırılarak üzerimize saldırtacağı haberini gönderip mümessilimizi kabul etmeyen sarıklılardan birisi" diye bahsettiği Müftü Hacı Tevfik Efendi H. 1337 (1921) senesinin Kasım ayında Zile isyanı bastırılırken yakalandığı zatürreden vefat etmiştir.

2. Özalp, Yalçın: Mustafa Kemal ve Amasya (Basılmış Çalışma) Sah. 2.

3. Yetkin, Nafiz: "Mustafa Kemal Paşa'nın Amasya'ya ilk gelişleri" Sabah (AmasyaMahalli Gazete) 21 Ocak 1981 - Süreli makale. 
Kemal Paşa'nın maiyetindekilerden Hüsrev Gerede ${ }^{4}$ aynı günü şöyle anlatiyor.

"Havza'dan Amasya'ya gelişimizde şehre gelinceye kadar bizi karş1layan olmamışt1"s ama "En gönülden coşkun karşılama Amasya'da oldu." “...daha sonra azmî, heyecanı, hareketliliği ve karar kat'̂̂liği ile bizi hayran bırakan Müftü Hacı Tevfik Efendi yanındaki eşraf heyeti ile geldi neden yollara düştüğümüzün idrâki içinde olduğunu anlatan hava içinde, adeta minberden vaaz edercesine kelime ve harflerin üzerine basarak;

“...Beldemize hoş geldiğiniz Paşa... Bütün Amasya emrinizdedir. Gazanız mübarek olsun..." dedi.

“Asla beklemediğimiz bu hitâp aynı zamanda istikbâlin teşhisi gibi idi. Paşa elini uzatan bu mübarek insanın elini öpmek ister gibi eğildi. $\mathrm{O}$ üzerinde üniforması olan Anafartalar kahramanını muhabbetle kucakladı. Yanındaki zevatı bir bir tanıttı. Millî mücadelede ilk defa bütün bir şehir safhalarını öğrenme ihtiyacı duymadan, çetinliği besbelli vatan kurtuluşu mücadelesinin bayrağını açma kararındaki bir evlâdının safına katılıyor ve bunu mübarek bir din adamının rehberliği, delaleti, öncülüğü ile yerine getiriyordu. Paşa'nın çok yakınında idim. Kendisi memleketin içinde bulunduğu buhranı anlatmaya hazırlanır ve gayesi yolunda yardım ve anlayış beklerken bu beklemediği tasvip ve adetâ açık kart önünde öyle heyecanlandıki, bana döndü.

- Hüsrev.... Görüyor musun? Müftü Efendi Hazretleri ne söylüyor dedi. Ve o heyecan içinde diyeceğim ki o ilk günlerin en güzel, inandırıcı, aydınlatıcı konuşmasını yaptı.

Amasya Müftüsü Hacı Hafız Tevfik Efendi'nin o aydınlık, imanlı, hakiki Türk din adamlarının vatanperverlik ve hamiyet terkibi cümlesi, benim için Millî Mücadele'nin ilk Fetva'sıdır. Kahraman, fedakâr, âlicenap Amasya hălkı çok hürmet ettikleri ve değer verdiklerini ikâmetimiz sırasında her hadisede şâhid olduğumuz Müftülerinin sözüne kalbleri ve bedenleri ile sadık kaldılar."

Kutay, Cemal: Kurtuluşun ve Cumhuriyetin Manevi Mimarları, Ankara 1973; Sah. 280-281.

4. Kutay, Cemal, Aynı eser sah. 280.

5. Kutay, Cemal: Mustafa Kemal Paşa ve Amasya Müftüsü Hacı Hafız Tevfik Efendi. 67. Yılında Amasya Tamimi - Amasya Belediyesi Kültür Yayınları No.3 Samsun 1986, Sah. 21-25.

6. Kutay, Cemal; Mustafa Kemal Paşa ve Cumhuriyetin Manevi Mimarları, Ankara 1973, sah. 281.

7. Kutay, Cemal: Aynı kaynak, Sah. 280.

8. Kutay, Cemal; Mustafa Kemal Paşa ve Amasya Müftüsü Hacı Hafız Tevfik Efendi. 67. Yilında Amasya Tamimi, Hüseyin Menç, 1986, Sah. 24. 
Amasya Müftüsü Hacı Tevfik Efendi ile Mustafa Kemal Paşa arasındaki bu "Ilk günler" birliği bu değerli din adamının vefat tarihi olan 1921 'e kadar devam etti.

“...vakitsiz ölümü Ankara'yı tehdid eden Zile isyanını bastırabilmek için kendisinden yardımcı kuvvet isteyen Binbaşı Cemil Cahit Bey'in (Orgeneral rahmetli Cemil Cahit Toydemir) isteği ile topladığı milislerin başında bir elinde silah bir elinde namaz seccadesi sonuna kadar isyan sahasındaki hizmetleri sırasında zatürre olması ve o günlerin yetersiz tedavisinin şifaya yeter olmaması sebeb olmuş"9 tur. (Resim 1)

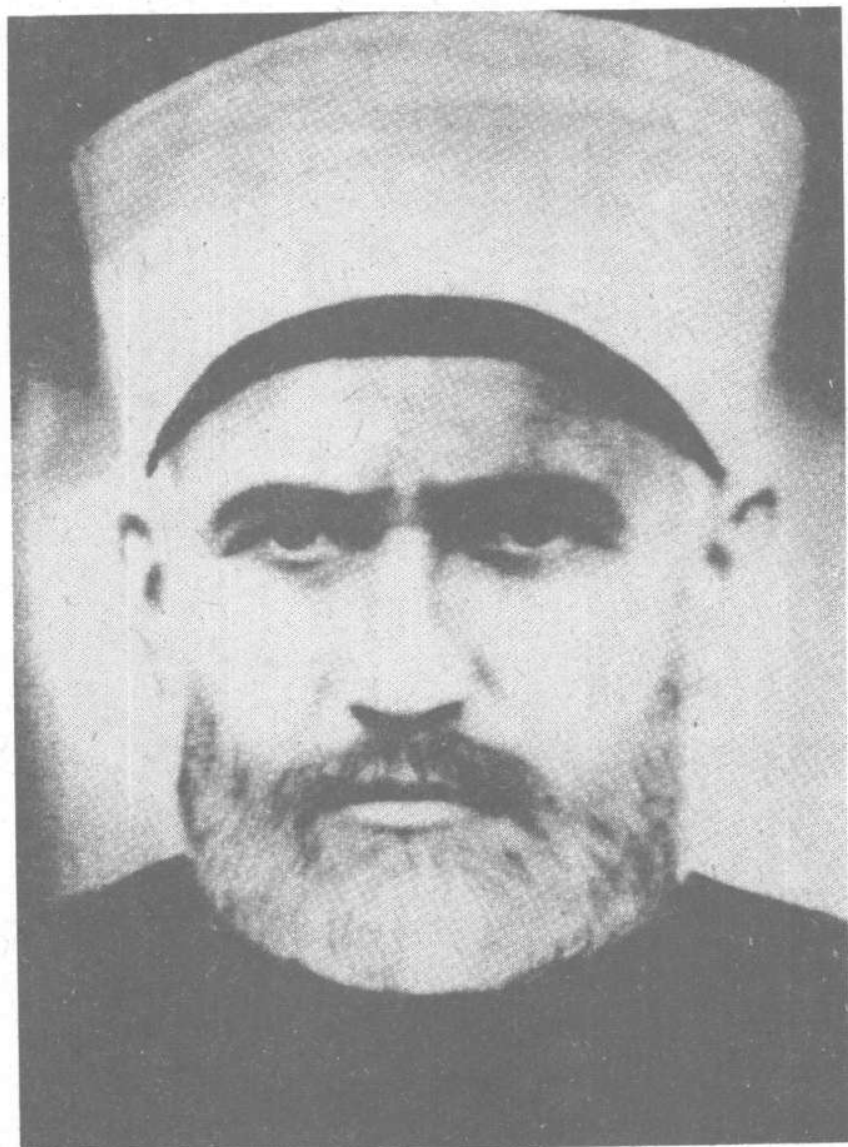

Resim 1: Amasya Müftüsü Hacı Tevfik Efendi.

9. Kutay, Cemal: Mustafa Kemal Paşa ve Amasya Müftüsü Hacı Hafız Tevfik Efendi. 67. Yılında Amasya Tamimi- Hüseyin Menç, Samsun-1986, Sah. 25. 


\section{ABDURRAHMAN KAMIL YETKIN}

Amasya'ya geldiği günün gecesini Yavuz Sultan Selim Han'ın doğduğu ve halk tarafından "Saray Düzü" diye bilinen yerdeki askerî kışlada (Resim 2) geçiren Paşa'yı ziyaret edenler arasında Sultan Bayezıd Camiî vaızı Abdurrahman Kâmil (Yetkin) Efendi de vardı ${ }^{10}$. Abdurrahman Kâmil Efendi o geceki ziyaretini şöyle anlatıyor;

“...o gece, yani perşembeyi cumaya bağlayan gece Mustafa Kemal Paşa'yı karanlık odada" ${ }^{11}$ ziyaret ettim. Konuşmalar bittikten sonra müsade istedim. Yarınki Cuma günü vaaz edeceğimi onun için erken gitmem gerektiğini söyledim ${ }^{i 2}$. Paşa ayağa kalkarak elimi öptükten sonra (-Baba ya-

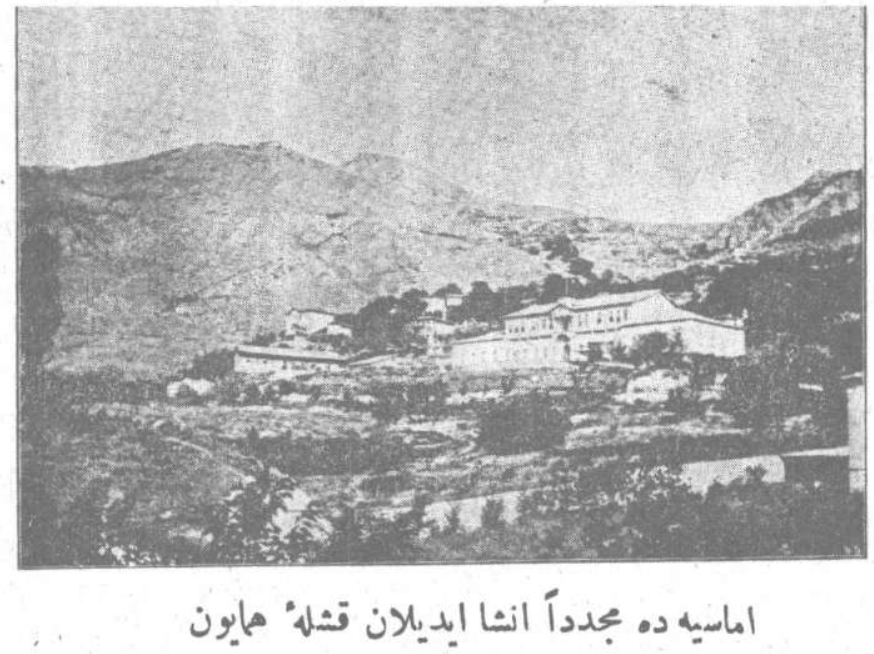

Resim 2. Ermenilerin ayaklanmaları iç karışıklıklar şeklinde tezahür edince, Amasya sancağı Alay merkezi yapılmı̧ ve bir tabur asker bulundurulması kararlaştırılmıştır.

Mutasarrıf Mehmed Kemâl Bey ve ihtiyat askerlerinin subayları tarafindan bir tabur Nizamiye askeri için 1316 (1898 ?) yılında "Eski Saray"ın ortasında inşaa edilen kışla binası.

10. Abdurrahman Kâmil Efendi: 1850-1941 yılları arasında yaşamıs olan Kâmil Efendi, Amasya'da doğmuş, ilk tahsiline sıbyan mektebinde başlamış Kur'an-1 Kerim'i hıfzından sonra imtihanla Ziya Paşa'nın yaptırdığı Rüştiye'ye girmiş. Diğer taraftan ağabeysi Alim Hafız Mustafa Sadık Efendi’den kıraat, Feraiz, arûz okumuş ve kadı olmuştur. Mir Hasan Efendi'den yedi yıl müddetTe Tefsir, Hâdis, usûl ve Hikmet okuyarak icazetnamesini almıştır. Istiklal Harbi Safahatında büyük hizmetler ifa etmiş uzun müddet halkı irşad eden bu zat-1 muhterem Şeyh Sadî'nin Bustan'ını Arapça olarak şerh etmiş, Makamat-1 Hariri'nin Türkçeye tercümesi üzerinde çalışmiștır.

11. (Karanlık oda): Mustafa Kemal Paşa'nın Amasya'ya geldiği sırada misafir edildiği kışlada kaldığı oda'dır. Daha sonra yıkılırken M. Kemal'in izni alınarak bu odanın yerine bugünkü heykeli dikilmiştir.

12. Demiray, Ahmet: Resimli Amasya (Tarih-Coğrafya-Salname-Kılavuz ve Kazalar) Ankara-1954, Sah. 142. 
nınıza adam katayım mı? Karanlıktır) dedi. (Gözlerimin ışığı beni götürür) diye cevapladım. Paşa tekrar elimi öperek (-Baba bu işte muaffak olmakta var, olmamakta var. İnşallah olacağız. Eğer olamazsak bizi asarlar, kelle gider ne dersin?) dedi. Bende (-Hey oğul sen ki genç yaşında başını vatan ve millet uğruna feda etmişsin koy benim bu ihtiyar kellede senin uğruna feda olsun.) dedim. Tekrar elimi öperek, yanıma Komser Osman Efendi'yi katarak uğurladı."13

"Sabah Kalktım camiye gitmek üzere hazırlanırken, kapı çalındı, açtım. Komiser Osman Efendi ile karşılaştım. Osman Efendi resmi bir selam verdikten sonra elimi öptü ve bir kağıt uzattı. (Paşa Hazretleri gönderdi bunu) dedi. Bende kağıdı aldım, öptüm ve başımın üzerine götürerek baş üstüne dedim." 14

“O günkü vaaz konum zekat-fitre hakkında idi. Paşa'dan gelen pusula üzerine vaaz konumu değiştirmek gerekti. Kısa bir zamanda ne hazırlanır? Vatanın kurtulması değilmi o kadar dedim. Camiye gittim. Cami kalabalık, halk abdest alıyor, namaza hazırlanıyordu. Mustafa Kemal Paşa ve arkadaşları da dolaşıyordu. Bu sırada ezan okundu namazı kıldıktan sonra nasihata başladım."15

Namaz bittikten sonra şüheda ruhuna ithaf edilmek üzere bir mevlid-i şerif okutuldu. $\mathrm{O}$ gün Amasya kasabası mahşeri bir kalabalık arz ediyordu. Bütün kaza halkı bu muazzam toplantıya iştirâk ve vatanî hizmetlerdeki vazifeleri paylaşmak için can atarak gelmiş bulunuyorlardi.

Mevlid-i şerif kıraatından sonra, cemaat-i islâmiye tam bir iman varlığı ile ellerini semaya doğru kaldırarak içten gelen samimi duadan sonra cami-i şeriften çıkarak, cami-i şerif haricindeki geniş sahayı bir anda doldurmuş bulunuyordu. Cemaatin kesafeti tahminen otuz binden fazla bundan eksik değildi. ${ }^{16}$

Yaptığımız araştırmalara göre Sultan Bayezid Camiinin bahçe kapısı üzerine çıkan"7 "Mustafa Kemal Paşa, hitabesine başlayıp, Türk Milletinin mukadderat-1 hakkındaki acı safahatı birer birer izaha çalışarak bir hiddet-i millîye ile bu geçirilen felâketin ancak refah yolunu aşabilecek geleceğine kâni olduğunu söylemekle nutkuna son verdikten sonra, ko-

13. Yetkin, Nafiz; "Mustafa Kemal Paşa'nın Amasya'ya ilk gelişleri” Sabah (AmasyaMahalli Gazete) 21 Ocak 1981-Süreli makale.

14. Aynı Kaynak, Sah. 2.

15. Aynı Kaynak, Sah. 3.

16. Osman Feyzi el Amasî; Amasya Meşahiri, 1952, Sah. 180-181, El yazma eser.

17. Yalçın Özalp'tan dinlenmiştir: "Rahmetli Babam Yusuf Kenan ve yine Rahmetli Hocam Ahmed Emri Yetkin ve Muammer Abi (Muammer Ülker Süleymaniye Kütüphanesi Müdürü)'den duyduğuma göre. 
nuşma hakkını muhterem üstadımız ${ }^{18}$ Abdurrahman Kâmil Efendi Hazretlerine tevdî buyurdu. Ve üstad-1 muhterem söze başlayarak dediki:

\section{"Muhterem Evlâtlarım!}

Paşa Hazretlerinin açıkca izahatta bulundukları Türk Milletinin, Türk Hakimiyetinin artık hikmet-i mevcudiyeti kalmadığı tahakkuk edince ve milletimizin mukadderat-1 endişeli bir duruma düşünce artık bu devletin mevcudiyetine hürmet etmek bence doğru bir yol değildir. Mademki milletimizin şerefi, haysiyeti, hürriyeti, istiklâli tehlikeye düşmüştür, artık başımızdaki bu hükümetten bir iyilik ummak bence abestir. Şu andan itibaren padişah olsun, isim ve ünvanı ne olursa olsun hiçbir şahsın ve makamın hikmet-i mevcudiyeti kalmamıştır. Yeğane çare-i halas halkımızın doğrudan doğruya hakimiyetini eline alması ve iradesini kullanmasıdır.

Binaenaleyh işte size "Hazret-i Ömer gibi bir Başbuğ" diye Mustafa Kemal Paşa'yı gösteriyor ve kendileri de Paşa'ya yönelerek:

\section{Muhterem Paşa Hazretleri;}

Şu görmüş olduğunuz Türk Evlatlarının heyet-i umumiyesi başta ben olmak şartıyla şu andan itibaren size biat etmiş bulunmaktayız. Vatan ve Milletimizin refah yolunu buluncaya kadar sizlerle el birliği yapacaklarına söz veriyoruz." diye hitabelerine son veriyor. Ve bu suretle millî mücadelenin ilk temel taşı burada atılıyordu. ${ }^{19}$ (Vesika-1)

Amasya Tamiminin hazırlanma arifesinde ki bu ve buna benzer hadiselerin "Amasya halkı da başta Müftü Hacı Tevfik Efendi, Hoca Abdurrahman Kâmil Efendi ve Şeyh Cemaleddin Efendiler olmak üzere millî irâdeye geçişte ve Millî Mücadeleye başlamada Mustafa Kemal Paşa'ya destek olmuşlardır"20 ve bu maya çok geçmeden tutmuştur.

Ertesi günü Selağzid ${ }^{21}$ meydanındaki Atik-i Ali mektebinde toplanan Amasyalılar "Müdafa-i Hukuk Cemiyeti"ni kurdular. Bu cemiyetin ilk

18. Osman Feyzi el Amasî'nin el yazması eserinde bu konuşmanin 19 Haziran 1919'da yani Mustafa Kemal Paşa'nın Amasya'ya gelişinin ikinci haftası olarak kabul ediliyor. Diğer kaynaklarda ise, 13 Haziran 1919 olduğu kanaati yaygındır.

19. Osman Feyzi el Amasî; aynı eser, sah. 181.

20. Kodaman, Bayram: İstiklâl Beyannâmesi'nin ilânı için Neden Amasya seçilmiştir. 67. Yılında Amasya Tamimi - Hazırlayan: Amasya Belediyesi Kültür Servisi Adına Hüseyin Menç, Amasya Belediyesi Kültür Yayınları No.3, Amasya-1986, Sah. 10.

21. Selağzı, Amasya halkı arasında bu isimle tanınan yer Sinan Paşa Hamamı-Gümüslü Cami-i ve Kesikbaş Evliyasının bulunduğu yerden geçen dere dolayısıyla bu isimle anılmaktadır. Yavuz Sultan Selim Han'ın ilk tahsile başladığı medresenin de burada bulunması dolayısıyla bugün Yavuz Sultan Selim Meydanı diye anılmakta ve Atatürk ile Milli Mücadeledeki arkadaşları ve Gabaş Ali'nin heykeli bulunmaktadır. 
maddi yardımı yine Abdurrahman Kâmil Efendi'nin bir mendil içinde Mustafa Kemal Paşa'ya verdiği beş altun oldu. ${ }^{22}$

Mustafa Kemal Paşa'nın beş yıl sonra Amasya'ya gelişlerinde hatıralarını yad ederken Abdurrahman Kâmil Efendi için şunları anlatmıştı:

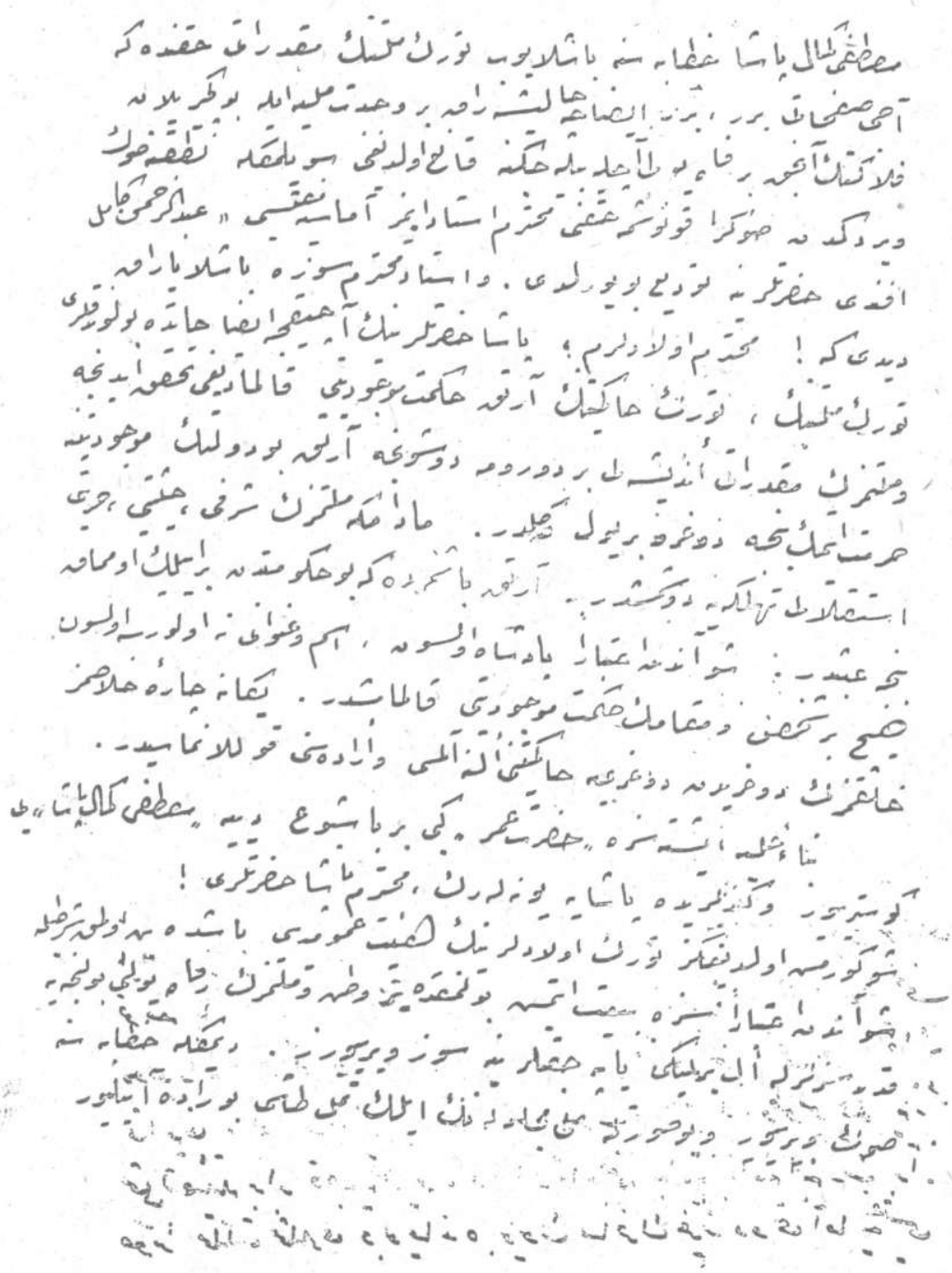

Vesika 1. Osman Feyzi El Amaŝ̂'nin hat'tı ile Abdurrahman Kâmil Efendi'nin Hutbesi

22. Kutay, Cemal: Millî Mücadele Hutbesi ve Abdurrahman Kâmil Efendi, 67. Yılında Amasya Tamimi- Hüseyin Menç, Samsun- 1986, Sah. 30. 
"Bundan beş sene evvel buraya geldiğim zaman bütün millet gibi vaziyet-i hakikiyeyi anlayamamışlardı. Fikirlerde teşevvüş vardı. Dimalar adetâ durgun bir haldeydi. Ben burada birçok zevatla beraber Kâmil Efendi Hazretleriyle de görüştüm. Bir camîi şerifte hakikati halka izah ettiler. Efendi Hazretleri Halka dedilerki: "Milletin şerefi, haysiyeti, hürriyeti, istiklâli hakikaten tehlikeye düşmüştür? Bu felâketten kurtulmak icab ederse vatanın son ferdine kadar ölmeyi göze almak lâzımdır. Padişah olsun, isim ve ünvanı ne olursa olsun hiç bir şahıs ve makamın hikmet-i mevcudiyeti kalmamıştır. Yegâne çare-i halas halkın doğrudan doğruya hâkimiyeti ele alması ve iradesini kullanmasıdır.

İşte Efendi Hazretlerinin bu mürşidane vuku bulan vaiz ve nasihatından sonra herkes çalışmaya başladı. Bu münasebetle (Müftui) Kâmil Efendi Hazretlerini yâd ediyorum. Genç Cumhuriyetimiz bu gibi ülema ile iftihar eder."23

“Ulu önder Ata'mız, Cumhur Başkanı Mustafa Kemal Paşa Hazretleri, Tokat'a giderken 19 Eylül 1928 'de Amasya'mızı şereflendirdi. Atatürk, Ankara'dan Amasya'ya özel trenle geldi... Amasya Müftüsü olan dedem Abdurrahman Kâmil Efendi'de karşılayanlar arasında idi. Dedem ihtiyar olduğu için yanında yardımcı olarak bunuluyordum. Uzaktan trenin düdük sesi duyuldu, halk kaynaştı, alkışlarla "Hoşgeldin Paşam" sesleri ufukları çınlatıyordu... Tren durdu, kapı açıldı. Atamız trenin sahanlığından bir basamak inerek, ikinci basamakta durdu ve etrafına bakınarak ilk sözü: "Müftü Efendi nerede?" oldu. Halk açıldı ve dedeme yol verdi, bende dedemin koltuğuna girerek öne geçirdim. Dedem Serkisof marka saatini yeleğinin cebinde taşırdı ve saatinin bir ucu yeleğinin bir cebine takılı zincirin diğer ucuna bağlı olan saati de diğer cebinde bulunurdu. Yalnız bu saatin kurulmasına mahsus bulunan anahtarı da zincirin ucuna bağlı olarak dişarıda sallanırdı. Ata son basamaktan da inerek hiç konuşmadan gülümseyerek dedeme yaklaştı. Hemen gözüne çarpan köstekli saatin anahtarını okşarcasına tutarak: (Resim-3)

"Bu nedir? Cennetin anahtarımı yoksa? Verde cennete girelim" dedi. Dedemde; "O cennetin anahtarı nasil olur? Asıl cennetin anahtarı sende verde biz girelim." dedi. Atamız bu cevap karşısında hayret içinde gülerek; "Cennetin anahtarı bende nasıl olur" dedi. Müftü Efendi hemen şu cevabı verdi. "-Nasıl olurda anahtar sende olmaz, sen ki bu cahil halkı okutmak üzere alfabe getirdin, bundan âlâ cennetin anahtarı olur mu?" Cevabı üzerine Ata gülerek Müftü'nün koluna girdi. Beraberce istasyonda hazır bulunan otosuna binip Hükümet binasına gittiler." ${ }^{24}$

23. Yetkin, Nafiz; Millî Mücadele Hutbesi ve Abdurrahman Kâmil Efendi, Kale Aylık Siyasi Dergi, Yıl 1, Sayı 6, Sah. 8, Samsun-Tarihsiz.

Yetkin, Nafiz; Yaşayan Atatürk'ten Anılar-Atamız, 18 Eylül 1928'de Amasya'ya gelişine ait unutulmaz anım Sabah (Amasya Mahalli Gazete) 21 Ocak 1981.

24. Aynı kaynak, sah. 4. 
Millî Mücadelenin başlarında Mustafa Kemal Paşa'nın Amasyalı iki din adamı ile ilişkileri hakkındaki yukarıdaki malumat Mustafa Kemal, din ve din adamları arasındaki ilişkinin normal seyrini göstermektedir. ${ }^{25}$

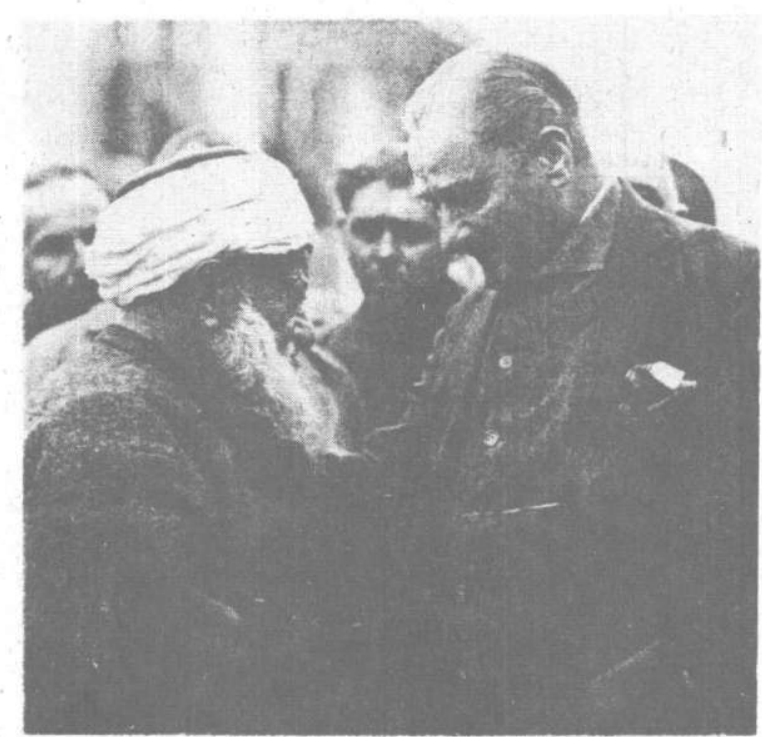

Resim 3: Amasya Müftüsü Kamil Efendi ve Atatürk 22 Kasım 1930

25. Karabekir, Kâzım; Istiklâl Harbimiz, İstanbul 1969, sah. 47.

Aydemir, Şevket Süreyya; Tekadam Mustafa Kemal, Ikinci Cilt, 1919-1922, İstanbul-1953, sah. 38.

Cebesoy, Ali Fuat; Mustafa Kemal (Millî Lider) Belleten, Cilt XX, Sayı 80, Ekim 1956. 